\title{
A systematic review of cognitive rehabilitation for bipolar disorder
}

\author{
Revisão sistemática sobre reabilitação cognitiva para o transtorno bipolar
}

\author{
Bruno Kluwe-Schiavon, ${ }^{1}$ Thiago Wendt Viola, ${ }^{1}$ Mateus Luz Levandowski, ${ }^{1}$ Vanessa Rezende Bortolotto, ${ }^{1}$ \\ Leo Schuch Azevedo e Souza, ${ }^{2}$ Saulo Gantes Tractenberg, ${ }^{1}$ Tárcio Soares ${ }^{2}$
}

\begin{abstract}
Introduction: It has been shown that bipolar disorder (BD) has a direct impact on neurocognitive functioning and behavior. This finding has prompted studies to investigate cognitive enhancement programs as potential treatments for $\mathrm{BD}$, primarily focusing on cognitive reinforcement and daily functioning and not restricted to psychoeducation and coping strategies, unlike traditional psychosocial treatments.

Objective: This study presents a systematic review of controlled trials of cognitive rehabilitation (CR) for BD. Our main objective is to describe the results of studies of rehabilitation programs for $\mathrm{BD}$ and related methodological issues.

Method: Electronic database searches (MEDLINE, Web of Science, and Embase) were conducted to identify articles using terms related to $B D$ and $C R$. The methodological quality of each article was measured using the 5-item Jadad scale.

Results: A total of 239 articles were initially identified, but after application of exclusion criteria, only four were retained for this review. An average of 17 hours of intervention sessions were conducted, distributed as 0.95 hours per week and three of the four studies reported better executive function performance after CR interventions.

Conclusions: We did not find robust evidence to support cognitive rehabilitation as an effective treatment for $B D$, because of: 1 ) the variety of intervention designs; 2 ) the methodological limitations of the studies; and 3) the lack of studies in the field. Keywords: Neuropsychology, mood disorders, cognition, cognitive training, remediation.
\end{abstract}

\section{Resumo}

Introdução: Tem sido demonstrado que o transtorno bipolar (TB) tem um impacto direto sobre o funcionamento neurocognitivo e o comportamento. Tais achados têm fomentado outros estudos para investigar o efeito de programas de aprimoramento cognitivo como potenciais intervenções no TB, focados principalmente no treino cognitivo e no funcionamento diário e não restrito a psicoeducação e estratégias de enfrentamento de problemas, como os tratamentos psicossociais tradicionais.

Objetivo: Este estudo apresenta uma revisão sistemática de ensaios clínicos controlados que avaliaram reabilitação cognitiva (RC) para TB. Nosso objetivo principal é descrever os resultados desses estudos acerca de programas de reabilitação para TB e questões metodológicas relacionadas.

Métodos: Foram realizadas pesquisas em bancos de dados (MEDLINE, Web of Science e Embase) para identificar artigos utilizando termos relacionados a RC e TB. A qualidade metodológica de cada artigo foi mensurada usando a escala JADAD de 5 itens. Resultados: Um total de 239 artigos foram identificados inicialmente, dos quais apenas quatro foram analisados nesta revisão após aplicação dos critérios de exclusão. Uma média de 17 horas de sessões de intervenção foram realizadas, com uma distribuição de 0,95 horas por semana. Três dos quatro estudos relataram meIhor desempenho na função executiva após intervenções de RC.

Conclusões: Não foram encontradas evidências suficientes que sustentem a reabilitação cognitiva como um tratamento efetivo do TB, devido: 1) à variedade de modelos de intervenção; 2) às limitações metodológicas dos estudos; e 3) à escassez de estudos na área.

Descritores: Neuropsicologia, transtornos de humor, cognição, treino cognitivo, remediação.

\footnotetext{
${ }^{1}$ Developmental Cognitive Neuroscience Research Group, Pontifícia Universidade Católica do Rio Grande do Sul (PUCRS), Porto Alegre, RS, Brazil. ${ }^{2}$ Department of Psychology, PUCRS, Porto Alegre, RS, Brazil.

Financial support: none.

Submitted Jan 21 2015, accepted for publication May 19 2015. No conflicts of interest declared concerning the publication of this article.

Suggested citation: Kluwe-Schiavon B, Viola TW, Levandowski ML, Bortolotto VR, Azevedo e Souza LS, Tractenberg SG, et al. A systematic review of cognitive rehabilitation for bipolar disorder. Trends Psychiatry Psychother. 2015;37(4):194-201. http://dx.doi.org/10.1590/2237-6089-2015-0006
} 


\section{Introduction}

There is a growing body of evidence supporting the view that psychiatric disorders are brain diseases that have impacts on neurocognitive functioning and behavior. According to criteria set out in the Diagnostic and Statistical Manual of Mental Disorders, Fifth Edition (DSM-5), bipolar disorder (BD) is a chronic illness characterized by recurrent episodes of mania and depression and it has been extensively associated with neurocognitive dysfunctions that interfere in daily functioning, ${ }^{1}$ autonomy and quality of life, psychosocial activities, disability-adjusted years of life, ${ }^{2}$ and workforce productivity. ${ }^{3}$ Specifically, there is evidence that people with BD perform poorly in neuropsychological tasks involving attention, memory, working memory, executive functions (such as planning, behavior inhibition and cognitive flexibility) and social cognition (e.g. theory of mind and emotion recognition). Additionally, recent studies have detected an association between frontotemporal abnormalities and decline in intelligence quotient (IQ) in patients with $\mathrm{BD},{ }^{4}$ and some authors have suggested that there could be similarities to neurodegenerative symptoms. ${ }^{5}$

Cognitive rehabilitation (CR) programs are generally described as the process of restoring and/or compensating for and/or training cognitive skills that have been impaired by pathological processes. ${ }^{6}$ These methods were originally designed to help patients with neurological conditions, but their applications were later extended to include treatment of psychiatric disorders. ${ }^{6,7}$ Therefore, given that individual and social impairments during the course of BD are usually related to persistent and progressive cognitive impairment, ${ }^{8-11}$ CR programs have emerged as a potential adjunctive treatment for BD. The primary focus of CR programs is on cognitive enhancement and daily life functioning and is not restricted to psychoeducation and coping strategies, unlike traditional psychosocial treatments.

Notwithstanding, most of the literature on applications of $\mathrm{CR}$ in psychiatric disorders describes it as a promising therapeutic option for cognitive deficits in schizophrenia and related disorders. ${ }^{12-14}$ Furthermore, there are a variety of methodological differences between different CR programs, in terms of the frequency of interventions and total duration, stimulation procedures employed (computer-based and/or paper-and-pencil) and approach (functional adaptation and/or general stimulation and/or specific cognitive training). ${ }^{14}$ For example, we recently reported that greater cognitive improvements in schizophrenia cognitive symptoms were observed when CR programs were planned with interventions of 3 hours per week for 24 weeks, including both process-specific and general stimulation approaches. ${ }^{14}$ Along the same lines, the purpose of this study was to perform a systematic review of controlled trials of $C R$ for $B D$, in order to extend applications to other psychiatric disorders. Our main objective is to describe the results and methodological issues of studies investigating rehabilitation programs for $\mathrm{BD}$.

\section{Methods}

\section{Procedure}

Searches were performed on the MEDLINE, Web of Science, and Embase databases for studies published from the first available date up to September 2014. All procedures were conducted in accordance with a checklist incorporating Cochrane Collaboration recommendations. ${ }^{15}$ The search terms used were ["bipolar disorder"] AND ["cognitive rehabilitation" OR "cognitive remediation" OR "cognitive training" OR "cognitive enhancement" OR "neurocognitive enhancement" OR "neuropsychological remediation" OR "neuropsychological rehabilitation" OR "neuropsychological training"]. Studies were selected for review if their titles and/or abstracts contained the key terms. The search was limited to studies with humans and both clinical trials and randomized clinical trials were included. The exclusion criteria were articles in languages other than English, interventions not involving rehabilitation, articles describing uncontrolled trials and trials without participants with BD. Additionally, the database search was supplemented by a review of references.

\section{Measurement}

Eligibility was assessed independently in a nonblinded standardized manner. The first and second authors screened the full texts of studies and any discrepancies were discussed until a consensus was reached. The authors also screened the references listed by each article selected.

The methodological quality of each study was measured using Jadad scores. ${ }^{16}$ The Jadad score is calculated using a five-item scale. Each question is answered with either yes (one point) or no (zero points). The scale covers the following elements: a) whether studies are randomized, b) whether studies are double blinded, c) whether studies describe withdrawals and dropouts, d) whether the 
randomization method is appropriate and e) whether the blinding method is appropriate.

\section{Categorization of interventions}

The intervention programs investigated in each study were categorized according to their designs, approaches and modalities. The design category differentiated paper-and-pencil programs from the computer-based ones. There were three approach categories: general stimulation programs, processspecific training and functional adaptation. Programs that did not focus on a specific cognitive process were classified as general-stimulation, since training covered a broad combination of different cognitive processes such as problem solving and planning. Programs that were highly focused on each cognitive process were classified as process-specific. This category covered programs that had specific exercises designed to improve a specific cognitive skill, such as attention or memory. Programs designed to improve daily-life functioning in general, such as routine planning and social skills for example, were allocated to the functional adaptation category. Finally, the cognitive programs were also classified according to modality (individual, group or mixed).

\section{Results}

The initial search returned 239 articles, which were screened according to the eligibility criteria (see flowchart in Figure 1). This process resulted in selection of four studies for the review.

\section{Methodological quality}

Table 1 provides a summary of the methodological quality scores for each of the controlled trials selected and their primary characteristics in terms of samples and measures. Two studies scored 5 points and the other two studies scored 1 point each. One of the studies that scored 1 point according to the Jadad system (Deckersbach et al. ${ }^{17}$ ) was not a randomized controlled trial, but a clinical trial and as such it did not have randomization or blinding procedures. The other study scoring 1 point (Preiss et al. ${ }^{18}$ ) assigned participants to intervention or control groups using pairwise diagnosis matching.

Figure 1 - Flowchart illustrating systematic review. 
Table 1 - Methodological quality and primary characteristics of the studies

\begin{tabular}{|c|c|c|c|c|}
\hline ID & Jadad & Study & Total sample (mean age) & Measures \\
\hline 1 & 1 & Deckersbach et al. ${ }^{17}$ & $14(36.8 \pm 7.8)$ & $\begin{array}{l}\text { Clinical: HAMD-17, YMRS } \\
\text { Occupational functioning: HPQ } \\
\text { Psychosocial functioning: LIFE-RIFT } \\
\text { Executive functioning: FrSBe, RBANS, TMT, CS } \\
\text { IQ: WTAR }\end{array}$ \\
\hline 2 & 5 & Lahera et al. ${ }^{19}$ & $37(39.2 \pm 10.1)$ & $\begin{array}{l}\text { Emotion perception: FEIT, FEDT } \\
\text { Emotion recognition: ER40 } \\
\text { Theory of mind: hinting task } \\
\text { Social cognitive bias: AIHQ } \\
\text { Clinical (depressive and manic symptoms): HAMD, YMRS } \\
\text { Psychosocial functioning: FAST, GAF-DSM-IV }\end{array}$ \\
\hline 3 & 1 & Preiss et al. ${ }^{18}$ & $31(44.2 \pm 14.2)$ & $\begin{array}{l}\text { Everyday functioning: CFQ } \\
\text { Cognitive functioning: DEX, EMQ } \\
\text { Psychological health: SOS-10 } \\
\text { Quality of Life: SQUALA } \\
\text { Clinical (depressive symptoms): BDI-II }\end{array}$ \\
\hline 4 & 5 & Torrent et al. ${ }^{20}$ & $239(39.4 \pm 9.0)$ & $\begin{array}{l}\text { Functional: FAST } \\
\text { Clinical: SCID } \\
\text { IQ: WAIS-III (vocabulary) } \\
\text { Processing speed: WAIS-III (digit-symbol coding, symbol search) } \\
\text { Executive functions: CWCST, SCWIT, FAS, TMTB, ROCF } \\
\text { Visual learning: ROCF, CVLT, WMS-III (LM) } \\
\text { Working memory: WAIS-III (arithmetic, digits, letter number sequencing } \\
\text { Attention: TMTA, CPT-II }\end{array}$ \\
\hline
\end{tabular}

$\overline{\mathrm{AIHQ}}=$ Ambiguous Intentions Hostility Questionnaire; BDI-II = Beck Depression Inventory; CFQ = Cognitive Failures Questionnaire; CPT = Continuous Performance Test-II; CS = Card Sorting; CVLT = California Verbal Learning Test; CWCST = Computerized Wisconsin Card Sorting Test; DEX = Dysexecutive Questionnaire; EMQ = Every Day Memory Questionnaire; ER40 = Emotion Recognition-40 Task; FAS = Controlled Oral Word Association Test; FAST = Functional Assessment Short Test; FEDT = Face Emotion Discrimination Task; FEIT = Face Emotion Identification Task; FrSBe = Frontal Systems Behavior Rating Scale; GAF $=$ Global Assessment of Functioning Scale; HAMD = Hamilton Depression Rating Scale; HAM-D-17 = Hamilton Depression Scale -17 item version; HPQ = Health Performance Questionnaire; ID = study identification; IQ = intelligence quotient; LIFE-RIFT = Longitudinal Interval Follow-up Evaluation-Range of Impaired Functioning Tool; LM = Logical Memory Scale; RBANS = Repeatable Battery for the Assessment of Neuropsychological Status; ROCF = Rey-Osterrieth Complex Figure; SCID = Structured Clinical Interview for DSM-IV; SCWIT = Stroop Color-Word Interference Test; SOS-10 = Schwartz Outcomes Scale - 10; SQUALA = Subjective Quality of Life Questionnaire; TMTA = Trail Making Test part A; TMT = Trail Making Test; TMTB = Trail Making Test part B; YMRS = Young Mania Rating Scale; WAIS-III = Wechsler Adult Intelligence Scale; WMS-III = Wechsler Memory Scale; WTAR = Wechsler Test of Adult Reading.

\section{Assessments}

Table 1 also lists all the neuropsychological, clinical and functional measures used in the studies. Because of the small number of studies selected and the differences in their primary objectives, their neuropsychological assessments employed a range of different tasks and tests. For example, Deckersbach etal. ${ }^{17}$ and Preiss etal. ${ }^{18}$ focused on psychosocial and daily life functioning. In contrast, both Lahera et al. ${ }^{19}$ and Torrent et al. ${ }^{20}$ focused specifically on cognitive functioning, but whereas the former emphasized social cognition and emotion recognition, the latter emphasized general cognitive processes (e.g. executive functions, processing speed, memory, and learning). With regard to clinical measures, just one study used the Structured Clinical Interview for DSM-IV (SCID) as a diagnostic measure. Two studies used a Hamilton Depression Scale (HAMD) and one used the Beck Depression Inventory (BDI).
Both studies that used a version of the HAMD also used the Young Mania Rating Scale (YMRS) to investigate symptoms of mania.

\section{Study design and follow-up}

All studies conducted baseline assessments with clinical, neuropsychological and functional measures. All of the post-treatment assessments were conducted at the end of the intervention periods. Only one study conducted a follow-up assessment. ${ }^{17}$ Figure 2 illustrates the total duration of interventions in weeks and the assessment points used in each study. Table 2 provides an overview of the $\mathrm{CR}$ and control interventions investigated in each study (frequency per week, total hours, general design, approach and modality, as well as intervention focus). An average of 17 hours of intervention sessions were conducted, distributed as 0.95 hours per week. 


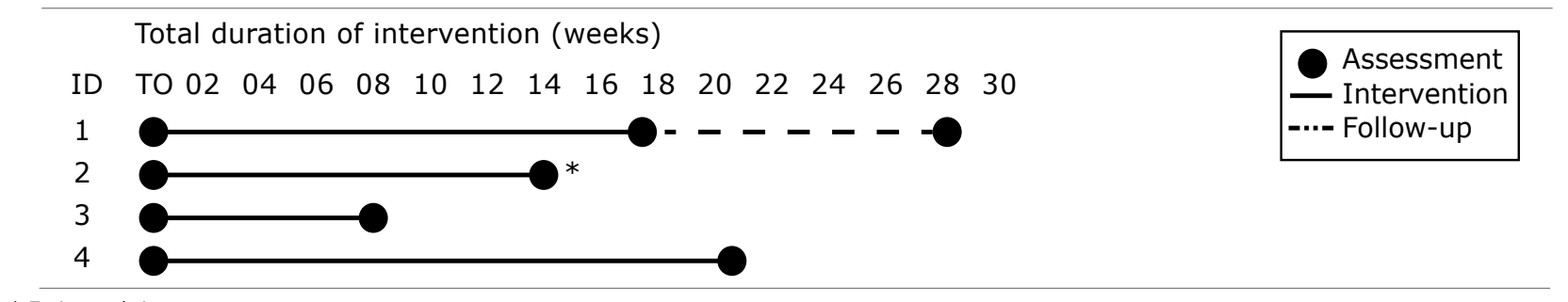

* Estimated time.

Figure 2 - Assessment, intervention and follow-up.

Table 2 - Characteristics of interventions

\begin{tabular}{|c|c|c|c|c|c|}
\hline ID & Interventions & $\begin{array}{c}\text { Sessions/week } \\
\text { (hours/week) }\end{array}$ & $\begin{array}{l}\text { Total } \\
\text { hours }\end{array}$ & Design & $\begin{array}{l}\text { Approach } \\
\text { (modality }\end{array}$ \\
\hline 1 & $\mathrm{CR}$ & $2(\sim 0.83)$ & 11.66 & $\mathrm{PP} / \mathrm{C}$ & GS/FA (i) \\
\hline \multirow[t]{2}{*}{2} & SCIT & $\mathrm{NR}(\sim 1)$ & $\sim 14$ & NR & PS/GS ( $g$ \\
\hline & TAU & NR (NR) & NR & NR & FA (i) \\
\hline \multirow[t]{2}{*}{3} & CT & $3(\sim 0.5)$ & $\sim 12$ & C & GS $(i) *$ \\
\hline & TAU & NR (NR) & NR & - & $\mathrm{FA}(\mathrm{m})$ \\
\hline 4 & FRP & $1(1.5)$ & 31.5 & PP & GS/FA (i) \\
\hline & PE & $1(1.5)$ & 31.5 & - & FA (i) \\
\hline
\end{tabular}

TAU

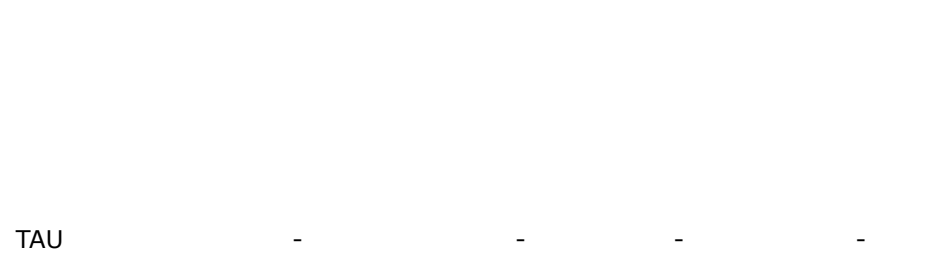

$-$

$\begin{array}{ll}\text { y) } & \text { Intervention focus } \\ \text { (i) } & \text { 1) Mood monitoring }\end{array}$

2) Organization and planning

3) Attention and memory

2) Enhancing functioning in daily routine

PE

1) Psychoeducation

2) Illness awareness

3) Treatment adherence

4) Early detection of prodromal symptoms of relapse

5) Lifestyle regularity TAU

1) Pharmacological treatment

$\overline{\mathrm{C}}=$ computer-based $; \mathrm{CR}=$ cognitive rehabilitation; $\mathrm{CT}=$ cognitive training; $\mathrm{FA}=$ functional adaptation; $\mathrm{FRP}=$ functional remediation program; $\mathrm{g}=\mathrm{group}$ sessions; GS = general stimulation; $\mathrm{i}=$ individual sessions; $\mathrm{ID}=$ study identification; $\mathrm{m}=$ mixed sessions; $\mathrm{NR}=$ not-reported; $\mathrm{PE}=\mathrm{psychoeducation}$; $\mathrm{PP}=$ paper-and-pencil; PS = process specific; SCIT = Social Cognition and Interaction Training; TAU = treatment as usual.

* Tailored to each individual's strengths and weaknesses.

\section{Outcomes}

Table 3 summarizes the main outcomes of the studies selected. Three of the four studies detected better executive function performance after cognitive rehabilitation interventions, measured by self-administered scales or questionnaires. However, none of the studies demonstrated cognitive improvements using neuropsychological tests or tasks. Social cognition and interaction training (SCIT) was the only intervention that provided some evidence of improvement in skills measured by social cognitive tasks (e.g. Hinting Task). There were notable increases in social cognition, 
Table 3 - Sample characteristics and main outcomes

\begin{tabular}{|c|c|c|c|c|c|c|c|}
\hline ID & Int. & Mean IQ (SD) & $\begin{array}{l}\text { Years of } \\
\text { study }\end{array}$ & Female (\%) & BD-1 (\%) & Comorbidities (\%) & $\begin{array}{c}\text { Pairwise comparison } \\
\text { between pre and post } \\
\text { intervention }\end{array}$ \\
\hline 1 & $\mathrm{CR}$ & $105.9(7.2)$ & $14.5(2.3)$ & 53 & $\sim 80$ & 0 & $\begin{array}{c}\text { Time effect: to < t1 (lost work } \\
\text { performance, }{ }^{*} \text { presenteeism, } \\
\left.\text { psychosocial functioning }{ }^{+}\right) ; \text {to }> \\
\left.\text { t1 (executive dysfunction }{ }^{\ddagger}\right)\end{array}$ \\
\hline \multirow[t]{2}{*}{2} & SCIT & NR & - & 76 & 71 & 13 & \multirow{2}{*}{$\begin{array}{c}\text { Group effect: SCIT > TAU } \\
\text { (Theory of Mind, }{ }^{+} \text {emotional } \\
\text { recognition, }{ }^{+} \text {emotional } \\
\text { perception*) }\end{array}$} \\
\hline & TAU & NR & & 50 & 81 & 13 & \\
\hline \multirow[t]{2}{*}{3} & $\mathrm{CT}$ & NR & - & 66 & NR & NR & \multirow[b]{2}{*}{$\begin{array}{c}\text { Group effect: } \mathrm{CT} \mathrm{t} 1<\mathrm{TAU} \text { t1 } \\
\text { (depressive symptoms }^{+} \text {) } \\
\text { Time effect }(\mathrm{CT}): \mathrm{t} 0>\mathrm{t} 1 \\
\text { (depressive symptoms, }^{+} \\
\text {everyday functioning, }^{*} \\
\text { cognitive functioning } \\
\text { Time effect }(\mathrm{TAU}): \mathrm{t} 0{ }^{+} \\
\text {t1 (everyday functioning, } \\
\text { cognitive functioning }^{+} \text {) }\end{array}$} \\
\hline & TAU & NR & & 56 & NR & NR & \\
\hline \multirow[t]{3}{*}{4} & FRP & $105.9(12.5)$ & $12.6(4.0)$ & NR & NR & NR & \multirow{3}{*}{$\begin{array}{l}\text { Time vs. group effect: FRP }> \\
\text { TAU (functional assessment*) }\end{array}$} \\
\hline & $\mathrm{PE}$ & $103.2(11.6)$ & $13.2(3.6)$ & NR & NR & NR & \\
\hline & TAU & $107.6(14.3)$ & $13.2(3.5)$ & NR & NR & NR & \\
\hline
\end{tabular}

$\mathrm{CR}=$ cognitive rehabilitation; $\mathrm{CT}=$ cognitive training; FRP = functional rehabilitation program; ID = study identification; PE = psychoeducation; SCIT = Social Cognition and Interaction Training; TAU = treatment as usual; Int. = intervention; NR = not-reported; t0 = baseline; t1 = post-treatment; t 2 = follow-up 1 . $* p<0.01,{ }^{+} p<0.05,{ }^{*} p<0.001$.

emotional recognition and emotional perception. However, these findings were from studies with high risk of bias, since they did not report data on sample characteristics (e.g. baseline IQ), intervention design or duration. The lack of such information prevents an in-depth analysis of reasons that may have contributed to better performance by $\mathrm{BD}$ individuals at the end of the intervention, thereby hampering replication of data. Finally, all studies demonstrated some improvement in daily functioning due to CR programs.

It should be noted that the two studies that did not report years of study provided alternative measures. For example, Lahera et al. ${ }^{19}$ reported that $33 \%$ of the sample had a primary level of education, $47 \%$ had completed secondary education and $20 \%$ had a university degree. On the other hand, Preiss et al. ${ }^{18}$ assessed educational level using a 10-point scale and, while the authors stated that the intervention group did not differ from the control group in terms of educational level, they did not mention which scale was used. Only two of the studies controlled for baseline IQ and two studies did not report years of study. Therefore, it should be noted that the lack of information about estimated IQ could introduce bias into the analysis of the efficiency of treatments, especially of cognitive rehabilitation programs. Finally, three studies provided figures for withdrawals and dropouts. Deckersbach et al. ${ }^{17}$ reported five dropouts from 18 participants and Preiss et al. ${ }^{18}$ reported 21 dropouts out of 45 participants at study outset. Torrent et al. ${ }^{20}$ reported that $28.6 \%$ patients discontinued in the functional remediation group, $24.4 \%$ discontinued in the psychoeducation group, and $17.5 \%$ discontinued in the treatment-as-usual group. Only one study was categorized as a group intervention, while the others were classified as "mixed modality" (both individual and group sessions).

\section{Discussion}

The main aim of this systematic review was to describe the findings and methodological issues of studies of rehabilitation programs for $\mathrm{BD}$. While the interventions differed in terms of their epistemological bases, goals and main techniques, most of the studies found that, at the very least, CR improved everyday functioning. However, we did not find robust evidence to support cognitive rehabilitation as an effective treatment for BD, because of: 1 ) the variety of intervention designs; 2 ) the methodological limitations of the studies; and 3) the lack of studies in the field.

With regards to the range of variation of interventions, we found that all interventions focused on daily-life activities in addition to including general or specific training. This is in accordance with the premise that $C R$ can target training of cognitive skills in general. ${ }^{6}$ However, our results also show that each CR program had its own specific aims, such as emotional and social training ${ }^{19}$ or improvement of attention, memory and planning. ${ }^{17}$ Similarly, while most of the CR programs comprised a total of approximately 17 hours, they varied in terms of the number of session per week, from one ${ }^{20}$ to three. ${ }^{18}$ 
Notwithstanding the cyclical nature of the argument, these differences concerning intervention design can be explained by the lack of studies investigating this subject, which makes it difficult to standardize a $C R$ protocol. As a result, these interventions were designed on the basis of the authors' theoretical perspectives on the cognitive impairments seen in BD.

As was found in our previous study concerning CR programs for psychiatric diseases,${ }^{14}$ these data corroborate the literature reporting that both computer-based and paper-and-pencil interventions can improve cognitive and daily functioning. ${ }^{21}$ It is possible that differences in intervention duration, intensity, and approach could be responsible for differences in cognitive measures. The only study that reported cognitive improvement measured by a test (the Hinting test), rather than based on self-report scales that could easily be biased, was a study investigating SCIT, which combined general stimulation with cognitive training and functional activities in individual sessions. ${ }^{19}$ Unfortunately, the authors did not report the number of sessions per week or the CR procedures employed. The article published by Torrent et al. ${ }^{20}$ was an exception, describing the main topics of each session. We suggest that future studies should clearly describe their samples and intervention procedures with a view to enabling replication.

While this systematic review only included four studies, it should be noted that a search for studies was performed on three well-established databases. Moreover, the search was not restricted by publication date and the most important Medical Subject Headings (MeSH) terms in the field were used. In order to increase the number of articles selected, the reference lists were screened by three independent researchers. Even using these search procedures, few studies reporting clinical trials of $\mathrm{CR}$ for $\mathrm{BD}$ were identified, when compared to other psychiatric conditions such as schizophrenia, for which a meta-analysis of 26 studies was published in 2007.22

Three hypotheses were raised to explain this finding. First, cognitive rehabilitation for psychiatric disorders is a novel field of intervention. Despite the emergence of evidence supporting small to moderate effects from these interventions in several psychiatric and neuropsychiatric illnesses, such as schizophrenia, ${ }^{22,23}$ Parkinson's disease, ${ }^{24}$ and depression, ${ }^{12,25}$ most of these data were collected during the last decade. Therefore, it is possible that cognitive rehabilitation programs for $\mathrm{BD}$ are still ongoing and have not yet been described in publications, as is the case of the McGurk trial (NCT01683539), which we found in the Cochrane Central Register of Controlled Trials.

Second, there is the possibility of publication bias, by which statistically significant positive results of cognitive rehabilitation in $\mathrm{BD}$ are more likely to be published. However, such an effect cannot be quantified.

Finally, another important issue that should be addressed is that although several studies have revealed that patients with $\mathrm{BD}$ exhibit persistent cognitive dysfunctions, a recent meta-analysis has questioned this idea. ${ }^{26}$ The authors analyzed 12 studies aiming to quantify the magnitude of the differences between bipolar patients' cognitive performance at baseline and after a follow-up period, but no robust evidence was found to support the hypothesis that patients with BD have increased neuropsychological deficits over time. Notwithstanding study limitations (relatively short follow-up), these findings have raised doubts about the theoretical basis of $\mathrm{CR}$ for $\mathrm{BD}$. One hypothesis is that the large dysfunctional impairments observed by clinicians (i.e. lack of social ability, difficulties with planning and goal-oriented behavior) depict the results of long periods of recurrent dysfunctional mood episodes and several dysfunctional coping styles learned through environmental contingences and their consequences. Indeed, most psychological interventions that have detected evidence for the BD spectrum involved functional analysis of behavior, focusing primarily on interpersonal functioning, emotional dysregulation and daily-life routine. ${ }^{27-30}$

This review has shown that there is still a lack of clinical trials of cognitive rehabilitation for BD. Additionally, cognitive interventions have been following the same road map as interventions used with other psychiatric disorders, in a clear pattern. This pattern is the result of adaptation of previous interventions, which were not originally developed for BD, but for schizophrenia, and are based on neurological frameworks. Furthermore, although the interventions were designed to improve cognitive functioning, only one study used validated tests and other tasks to assess these outcomes. It is therefore suggested that future studies attend to this shortcoming, conducting consistent neuropsychological assessments. Unfortunately, it is not possible to state which interventions and characteristics are the key aspects in effective treatment for BD. This review has shown that there is still a lack of evidence that CR for BD results in improvements and that this a challenging field in need of study and testing.

\section{References}

1. Altshuler LL, Bearden CE, Green MF, van Gorp W, Mintz J. A relationship between neurocognitive impairment and functional impairment in bipolar disorder: a pilot study. Psychiatry Res. 2008;157:289-93.

2. Judd LL, Schettler PJ, Solomon DA, Maser JD, Coryell W, Endicott J, et al. Psychosocial disability and work role function compared across the long-term course of bipolar I, bipolar II and unipolar major depressive disorders. J Affect Disord. 2008;108:49-58. 
3. McIntyre RS, Wilkins $K$, Gilmour $H$, Soczynska JK, Konarksi JZ, Miranda A, et al. The effect of bipolar I disorder and major depressive disorder on workforce function. Chronic Dis Can. 2008;28:84-91.

4. Bruno SD, Papadopoulou K, Cercignani M, Cipolotti L, Ron MA. Structural brain correlates of IQ changes in bipolar disorder. Psychol Med. 2006;36:609-18.

5. Goodwin GM, Martinez-Aran A, Glahn DC, Vieta E. Cognitive impairment in bipolar disorder: Neurodevelopment or neurodegeneration? An ECNP expert meeting report. Eur Neuropsychopharmacol. 2008;18:787-93.

6. Twamley EW, Jeste DV, Bellack AS. A review of cognitive training in schizophrenia. Schizophr Bull. 2003;29:359-82.

7. Fisher M, Holland C, Subramaniam K, Vinogradov S. Neuroplasticity-based cognitive training in schizophrenia: an interim report on the effects 6 months later. Schizophr Bull. 2010;36:869-79.

8. Hellvin T, Sundet $K$, Simonsen $C$, Aminoff SR, Lagerberg TV, Andreassen $\mathrm{OA}$, et al. Neurocognitive functioning in patients recently diagnosed with bipolar disorder. Bipolar Disord. 2012;14:227-38.

9. Post RM, Fleming J, Kapczinski F. Neurobiological correlates of illness progression in the recurrent affective disorders. J Psychiatr Res. 2012;46:561-73.

10. Kapczinski F, Vieta E, Andreazza AC, Frey BN, Gomes FA, Tramontina J, et al. Allostatic load in bipolar disorder: implications for pathophysiology and treatment. Neurosci Biobehav Rev. 2008;32:675-92.

11. Moorhead TW, McKirdy J, Sussmann JE, Hall J, Lawrie SM, Johnstone EC, et al. Progressive gray matter loss in patients with bipolar disorder. Biol Psychiatry. 2007;62:894-900.

12. Li J, Theng YL, Foo S. Game-based digital interventions for depression therapy: a systematic review and meta-analysis. Cyberpsychol Behav Soc Netw. 2014;17:519-27.

13. Wykes T, Spaulding WD. Thinking about the future cognitive remediation therapy-what works and could we do better? Schizophr Bull. 2011;37:S80-90.

14. Kluwe-Schiavon B, Sanvicente-Vieira B, Kristensen $\mathrm{CH}$, GrassiOliveira R. Executive functions rehabilitation for schizophrenia: a critical systematic review. J Psychiatr Res. 2013;47:91-104.

15. Lundh A, Gotzsche PC. Recommendations by Cochrane Review Groups for assessment of the risk of bias in studies. BMC Med Res Methodol. 2008;8:22.

16. Jadad AR, Moore RA, Carroll D, Jenkinson C, Reynolds DJM, Gavaghan DJ, et al. Assessing the quality of reports of randomized clinical trials: is blinding necessary? Controll Clin Trials. 1996;17:1-12.

17. Deckersbach T, Nierenberg AA, Kessler R, Lund HG, Ametrano RM, Sachs G, et al. RESEARCH: Cognitive rehabilitation for bipolar disorder: An open trial for employed patients with residual depressive symptoms. CNS Neurosci Ther. 2010;16:298-307.
18. Preiss M, Shatil E, Cermakova R, Cimermanova D, Ram I. Personalized cognitive training in unipolar and bipolar disorder: a study of cognitive functioning. Front Hum Neurosci. 2013;7:108.

19. Lahera G, Benito A, González-Barroso A, Guardiola R, Herrera $S$, Muchada B, et al. Social-cognitive bias and depressive symptoms in outpatients with bipolar disorder. Depress Res Treat. 2012;2012:670549.

20. Torrent C, Bonnin Cdel M, Martínez-Arán A, Valle J, Amann BL, González-Pinto $A$, et al. Efficacy of functional remediation in bipolar disorder: a multicenter randomized controlled study. Am J Psychiatry. 2013;170:852-9.

21. Velligan DI, Kern RS, Gold JM. Cognitive rehabilitation for schizophrenia and the putative role of motivation and expectancies. Schizophr Bull. 2006;32:474-85.

22. McGurk SR, Twamley EW, Sitzer DI, McHugo GJ, Mueser KT. A meta-analysis of cognitive remediation in schizophrenia. Am J Psychiatry. 2007; 164:1791-802.

23. Anaya C, Martinez Aran A, Ayuso-Mateos JL, Wykes T, Vieta E, Scott J. A systematic review of cognitive remediation for schizoaffective and affective disorders. J Affect Disord. 2012;142:1321.

24. Ell SW. Targeted training of the decision rule benefits rule-guided behavior in Parkinson's disease. Cogn Affect Behav Neurosci. 2013;13:830-46.

25. Iacoviello BM, Wu G, Alvarez E, Huryk K, Collins KA, Murrough JW, et al. Cognitive-emotional training as an intervention for major depressive disorder. Depress Anxiety. 2014;31:699-706.

26. Samame C, Martino DJ, Strejilevich SA. Longitudinal course of cognitive deficits in bipolar disorder: a meta-analytic study. J Affect Disord. 2014;164:130-8.

27. O'Connell B, Dowling M. Dialectical behaviour therapy (DBT) in the treatment of borderline personality disorder. J Psychiatr Ment Health Nurs. 2014;21:518-25.

28. Fristad MA, MacPherson HA. Evidence-based psychosocial treatments for child and adolescent bipolar spectrum disorders. J Clin Child Adolesc Psychol. 2014;43:339-55.

29. West $A E$, Pavuluri MN. Psychosocial treatments for childhood and adolescent bipolar disorder. Child Adolesc Psychiatr Clin N Am. 2009;18:471-82, x-xi.

30. Goldstein TR, Axelson DA, Birmaher B, Brent DA. Dialectical behavior therapy for adolescents with bipolar disorder: a 1-year open trial. J Am Acad Child and Adolesc Psychiatry. 2007;46:820-30.

\section{Correspondence:}

Bruno Kluwe-Schiavon

Av. Ipiranga, 6681, prédio 11, sala 936

90619-900 - Porto Alegre, RS - Brazil

Tel.: +55 (51) 3320.3500, ext. 7740

E-mail: brunokluwe@gmail.com 